\title{
Tensile Properties and Volumetric Stability of Indigenous Woody Plant Materials under Different Seasoning Techniques
}

\author{
D. A. R. Dolage, T. M. Pallewatta and R. R. G. S. Bandara
}

\begin{abstract}
This research paper explores the possibility of using indigenous woody plant materials as the reinforcement for composite members in cement mortar. The objectives of the study are to ascertain the stress-strain relationship and volumetric stability of indigenous woody plant materials with respect to locally adopted seasoning techniques. The survey identified six woody plant materials namely Veval, Una, Tharana, Eraminiya, Kooratiya and Dodanpana, which are worthy of being investigated based on past knowledge. The two locally adopted seasoning techniques investigated in this research are air drying and heat treatment. The specimens subjected to air drying for seasoning record higher tensile strengths than the heat treated, with respect to all six materials investigated. While Dodanpana records the lowest variation in cross sectional area, Tharana, Kooratiya and Una also show relatively high stability in relation to shrinkage. Three out of the six woody plant materials investigated, Kooratiya Tharana and Dodanpana can be recommended as suitable to be used as reinforcements, in terms of tensile strength, cross sectional area stability and length stability. These materials could be utilized for replacing mild steel reinforcements in Reinforced Cement Mortar (RCM) composite members. RCM could be effectively adopted for relatively low stress level applications in rural areas, where the villagers can easily obtain such woody plant materials and season the same using traditional methods.
\end{abstract}

Keywords: Woody plant materials, Tensile strength, Volumetric stability, Alternative material

\section{Introduction}

On one hand, the current crisis of escalating steel prices evoked by recently developed countries has caused increasing concerns about the necessity for alternative materials. On the other, environmental degradation has urged us to direct our attention to search for nonpolluting materials and manufacturing processes, which require less energy.

In Sri Lanka, too, steel reinforcement prices have steadily increased over the years. However, not much evidence of research studies carried out to investigate the use of suitable alternative material which offer tensile strength, could be found. One direction for investigation could be to evaluate the relevant properties of suitable indigenous woody plant material that had been used in this context in the past.

Our ancestors used timber not only as structural members but also as the provider of tensile strength in composite members with clay. They have used woody plant materials for construction of clay walls, and Bissa (for storing grain) among other applications. The findings of a study [6] show that short discreet fibres of steel have been extensively used in cement concrete to accentuate certain favourable properties of the concrete. There have been studies [5] to investigate the feasibility of using vegetable fibres since large tensile strength of steel fibres is generally too much to derive favourable properties of concrete. In a study [5] authors have examined short discreet vegetable fibres namely, jute, coir and bamboo for their suitability for incorporation with cement concrete. Their study revealed that physical properties of these fibres have shown no deterioration in a concrete medium. This suggests that woody plant material too would have long term durability when used as a composite material.

Eng. (Dr.) D. A. R. Dolage, CEng, FIE(Sri Lanka), BSc Eng. (Moratuwa), MSc (Reading), MA (Colombo), MBA (SJP), DBA (UniSA), Senior Lecturer, Department of Civil Engineering, The Open University of Sri Lanka.

Eng. (Prof.) T. M. Pallewatta, Int. PEng., CEng., FIE(Sri Lanka), FIAE(SL), BSc. Eng. (Hons) (Moratuwa), MEng. (AIT), DEng. (Tokyo), Professor in Civil Engineering, Department of Civil Engineering, The Open University of Sri Lanka.

R. R. G. S. Bandara, BTech (Eng) (OUSL), PG Diploma in Business Management (Wayamba).Engineering Manager, Buddhika Construction Company. 
Aziz et al. [1] report on the research and developments for effective utilization of natural fibres from coconut husk, sisal, sugarcane bagasse, bamboo, jute, wood, akwara, plantain and musamba for making concrete. In a more recent study [3], the authors assessed the value of some commonly available tropical fibres for the composite industry starting with the determination of strength, E-modulus and strain to failure through single fibre tensile tests. The study concludes that when the composite industry looks for light reinforcements for their products, they have the option to choose natural fibres.

There has been a growing interest in using bamboo for making low cost composite materials in recent years. Researchers [3], [4] have done studies to assess tensile properties of bamboo and similar woody plant material. In remote areas of Sri Lanka villagers still opt to use natural indigenous woody plant materials in view of lower material and transport costs. The preliminary survey of this revealed that our ancestors had recognised the tensile properties of some of the woody plant materials namely, Veval (Cane), Una (Bamboo), eraminiya, kooratiya, tharana and dodanpana. While Veval and Eraminiya are vines, the others are stiff culms. These plant vines and culms are freely available in large quantities in Sri Lankan forests in the dry zone. It is clear that the most important mechanical property when selecting this type of a material for reinforcing applications is the tensile strength. Moreover, acquisition of these materials does not require felling of tress, since only the mature culms are obtained, hence a minimum damage to the environment.

There is no evidence of local studies that has investigated the tensile strengths of Veval, Una, eraminiya, kooratiya, tharana and dodanpana. Nor has there been any research work that investigated other relevant characteristics of these materials such as cross sectional area stability and the length stability that has a bearing on their suitability as reinforcing material to be embedded in cement mortar. Also the effectiveness of seasoning techniques such as heat treatment and air drying, practiced by villagers to minimise volumetric change and susceptibility to insect attack while improving strength, has not been explored.

Durability is a very important consideration when woody plant materials are used in construction process as a composite material.
The type of species and the degree of maturity of the culms used are the most important determinants of durability. The type of seasoning method adopted and its best practice also influences the durability. The period of seasoning depends on the initial moisture content of the woody plant material. The durability and the strength of the woody plant materials are also dependent upon their subsequent level of exposure to the environment.

The foregoing discussion identifies three gaps in the knowledge pertaining to the use of indigenous woody plant materials. Hence the objectives of the study are:

1) To identify the stress-strain relationship of woody plant materials in relation to seasoning techniques adopted locally.

2) To study volumetric stability of indigenous woody plant materials with respect to local seasoning techniques.

\section{Methodology}

There is ample evidence to the effect that our ancestors had used indigenous woody plant materials in erecting structures, as direct structural members as well as reinforcement elements in composite materials. Villagers from rural areas, who are still using these indigenous woody plant materials, were interviewed and information pertaining to the suitable woody plant materials was obtained. Twenty eight such rural residents selected from two Divisional Secretariats, Nikaweratiya and Rajanganaya, were interviewed. The interviews were structured primarily to obtain following information; commonly used indigenous woody plant materials of appreciable tensile strength and traditional seasoning techniques adopted to remove moisture from the materials.

\subsection{Selection of Indigenous woody plant materials}

A number of indigenous woody plant materials were selected for this research study from the information obtained from villagers. The woody plants which were chosen in view of their tensile properties are given below (their botanical names are given in parenthesis):

Veval (Calamus rotang L.)

Una (Bambusa vulgaris Schrad. ex Wendl.)

Eraminiya (Zizyphus oenoplia (L.) Mill.)

Kooratiya (Phyllanthus polyphyllus Willd.)

Tharana (Tarenna asiatica (L.) Alston)

Dodanpana (Glycosmis penta (Retz.) Corr.) 
The specimens of the woody plant materials selected for testing should be mature and free from defects. Hence, the specimens of the selected woody plant materials were cut only from reasonably mature sections of culms of the plants. Pertaining to each species, three pieces of specimen, each of length $120 \mathrm{~mm}$ were prepared. Thereafter, the bark was peeled off from the hard part of the culms. During this operation, adequate precautions were taken to ensure minimum damage to the outer surface of the hard part of the culms. If the outer surface of specimen is damaged in the process of peeling off, severing longitudinal fibres and resulting in an uneven surface, it could culminate in reduced strength values and distorted readings for shrinkage.

\subsection{Traditional methods of seasoning} indigenous woody plant materials

In general, woody plant materials are seasoned to accomplish three objectives which are given below:

- to increase the strength

- to improve volumetric stability

- to prevent the materials from insect attacks

There are several methods adopted by villagers to season indigenous woody plant materials:

\section{- Heat treatment method}

This is a very speedy and easy method to season the woody plant material. The main purpose of this treatment method is to reduce the moisture content of the indigenous woody plant materials through heating over an open flame. When the materials are sufficiently heated, moisture in the cell structure could evaporate. However, certain amount of skill and experience is required of the person carrying out the operation to arrive at the optimum seasoning without burning the material.

\section{- Open air drying method}

When compared to heat treatment method described above, this is a time consuming process. This method too, is primarily aimed at reducing the moisture content of the woody plant material through the transfer of moisture to air. Through this method more uniform seasoning could be achieved, with minimum damage to the material.
- Burying in the mud method

This seasoning method takes unduly longer time to ensure reaching the expected benefits. This process mainly enables the indigenous woody plant materials to develop a capacity to resist insect attacks, while subsequent air drying is necessary to reduce moisture.

Since burying in the mud method is not practiced widely among the villagers and also it is not aimed at reducing moisture, it was decided to compare only the first two techniques of seasoning indigenous woody plant materials. This enables to make a comparison between the effectiveness of the two methods.

\subsection{Application of heat treatment and air drying}

The seasoning of samples selected for testing was done by employing the two methods discussed above. The procedures adopted are described below.

\section{Heat Treatment}

The prepared test specimens were held over a specially prepared hearth while being slowly rotated and longitudinally moved forwards and backwards, so that the material surface is exposed to the flames as uniformly as possible. The duration of the treatment was maintained at around 15 minutes with indication for optimum treatment limit identified by colour change of the surface. Throughout the process, the specimen was kept at a distance of about $7 \mathrm{~cm}-10 \mathrm{~cm}$ from the hearth. Each piece was held over the hearth in this manner three times doing every other day.

\section{Air Drying}

The prepared test specimens were kept in the open air for drying. It took more than forty five days for the moisture content to reduce to an appreciable level. The test specimens were laid on a mesh and rolled over daily so that they are exposed to air uniformly.

\subsection{Testing Procedure}

From each species, twelve specimens were obtained for testing, six after heat treatment and six after air drying. Orthogonal readings of the diameter were obtained using a Micrometer gauge at the marked two ends and the middle of each specimen. Altogether, six diametric readings were taken per specimen per occasion. In this manner, measurements were taken daily on each specimen, for sixty days. 
For the determination of Tensile capacity and the stress-strain characteristics of the materials, a strain controlled Universal Testing Machine of $50 \mathrm{kN}$ capacity, with serrated Vee chucks for holding round materials was used.

\subsection{Measurement of Strain}

The serrated Vee chuck arrangement employed by the machine for holding test specimens works on the assumption that the required tensile force up to failure could be transferred by surface shear of the part being gripped by the chuck. Though this assumption holds true for most metals, it is bound to fail for anisotropic, soft fibrous materials like the woody plant material. This was indeed proven when initial tensile tests were done on samples with uniform cross sections as they tended to slip even at fractions of the tensile capacity.

Therefore, the test samples need to be formed in such a way, that there is adequate surface area at the ends to facilitate gripping by chucks while having a smaller cross section at the middle 'test length' to allow a lower failure load. In line with this concept, test specimens were formed as shown in the Figure 1, on a Lathe.

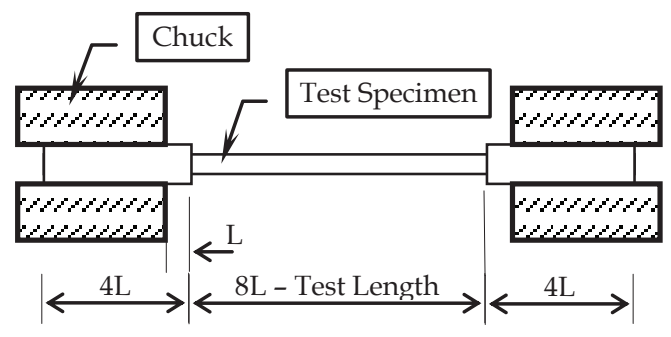

Figure 1 - Test specimen setup

In the process of reducing the diameter of the test specimen all possible precautions were taken not to damage the fibre of the material which otherwise could weaken the tensile strength of the specimen. Finally prepared test specimen would have half the diameter of the ends, at the middle 'test length'.

Further, the most reliable way to measure elongation of a test specimen is to use the cross head movement, which is obtainable from the transducers on the testing machine. However, if there is any slip in the chucks, this reading could become quite arbitrary as a measure of specimen elongation. Therefore, the use of a sample with reduced centre part, as shown in figure 1, would also facilitate accurate measurement of total elongation of a sample, finally leading to reliable evaluation of strain in 'test length'.

The simple calculations adopted for evaluating the strain in the test length of a specimen can be presented as below based on the assumptions of no slip at the chucks and uniform elastic modulus across the section.

Assuming elongations of thicker section beyond chuck (length $L$ ) is $e_{1}$ and test length (length $8 \mathrm{~L}$ ) is $\mathrm{e}_{2}$, the total elongation $\mathrm{e}=2 \mathrm{e}_{1}+\mathrm{e}_{2}$

By the basic theory, the Young' modulus E is related to stress and strain as given below in standard notation.

$$
\mathrm{E}=\mathrm{FL} / \mathrm{Ae} \quad \mathrm{e}=\mathrm{FL} / \mathrm{AE}
$$

For a given load ' $\mathrm{F}$ '

$$
\mathrm{e}_{1}=\mathrm{FL} / 4 \mathrm{AE} \quad \mathrm{e}_{2}=\mathrm{F} 8 \mathrm{~L} / \mathrm{AE}
$$

Therefore:

$$
\begin{aligned}
& \mathrm{e}=2(\mathrm{FL} / 4 \mathrm{AE})+(\mathrm{F} 8 \mathrm{~L} / \mathrm{AE}) \\
& \mathrm{e}=\mathrm{FL} / \mathrm{AE}[0.5+8]
\end{aligned}
$$

This shows that both enlarged end elongations is only $1 / 16^{\text {th }}$ of that of the test length. Hence, it is safe to approximate total elongation measured by machine cross head displacement, to elongation of the test length of the specimen.

Hence, the stress-strain relationships were calculated based on the above approximation.

\section{Results and Discussion}

\subsection{Stress-Strain relationship of woody plant materials}

The tensile stress in a specimen was computed by dividing the applied load by the cross sectional area of the test length of the specimen, while strain was evaluated by dividing the total elongation by the test length.

Figures 2 to 7 depict the stress-strain relationships of the six indigenous woody plant materials for both seasoning techniques of heat treatment and air drying. The tensile stress at the failure point is referred to as the tensile strength. Table 1 depicts the failure loads for the six types of woody plant materials for both seasoning techniques of heat treatment and air drying. This table facilitates easy comparison of tensile strength among the six species as well as between the seasoning techniques of heat treatment and air drying. While tharana culms under air drying recorded the highest tensile strength $\left(111.5 \mathrm{~N} / \mathrm{mm}^{2}\right)$, Veval $\left(17.7 \mathrm{~N} / \mathrm{mm}^{2}\right)$ 
gave the lowest. For heat treated seasoning, tharana culms recorded the highest tensile strength $\left(101.1 \mathrm{~N} / \mathrm{mm}^{2}\right)$, while Veval (14.9 $\mathrm{N} / \mathrm{mm}^{2}$ ) gave the lowest.

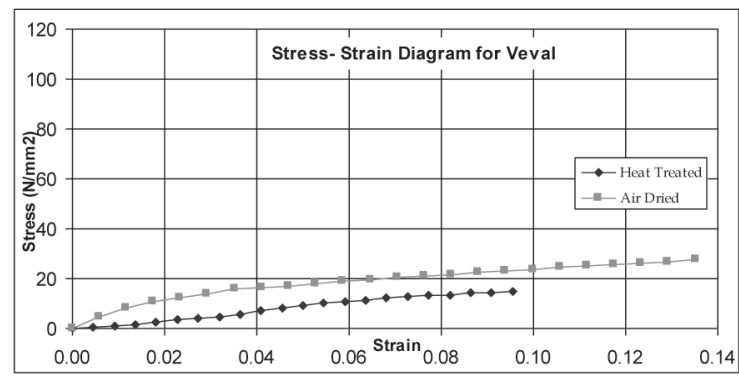

Figure 2 - Stress-Strain Diagram for Veval

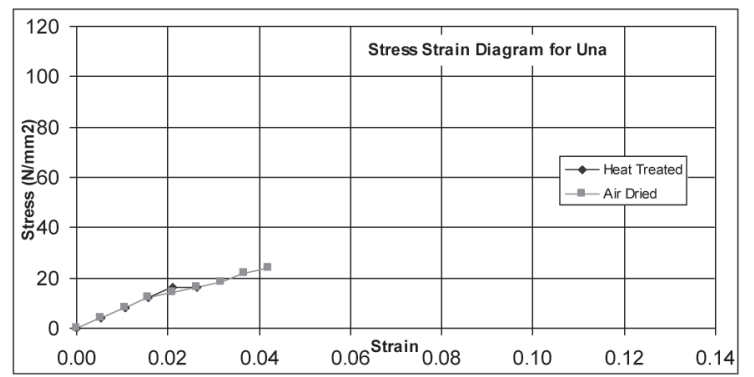

Figure 3 - Stress-Strain Diagram for Una

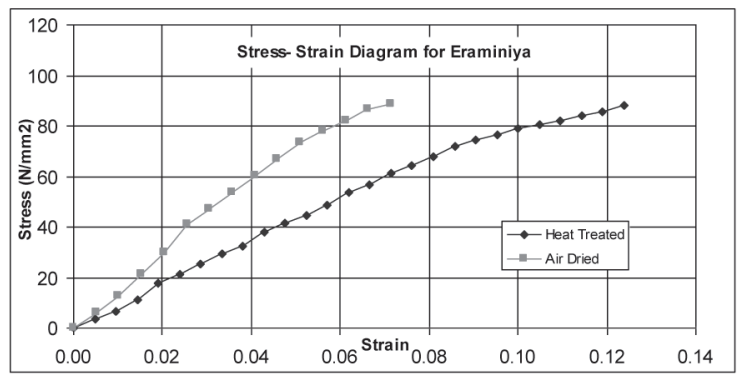

Figure 4 - Stress-Strain Diagram for Eraminiya

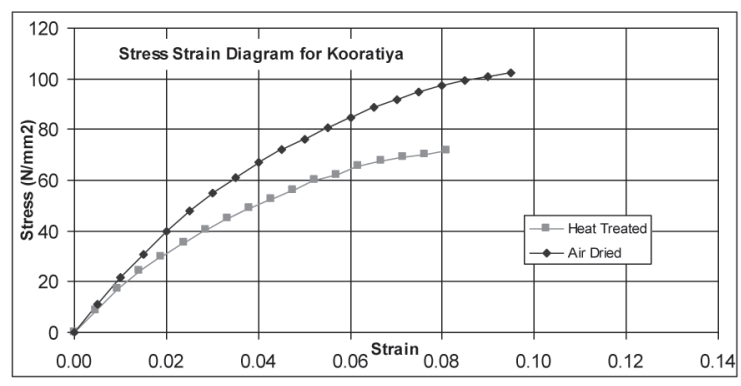

Figure 5 - Stress-Strain Diagram for Kooratiya

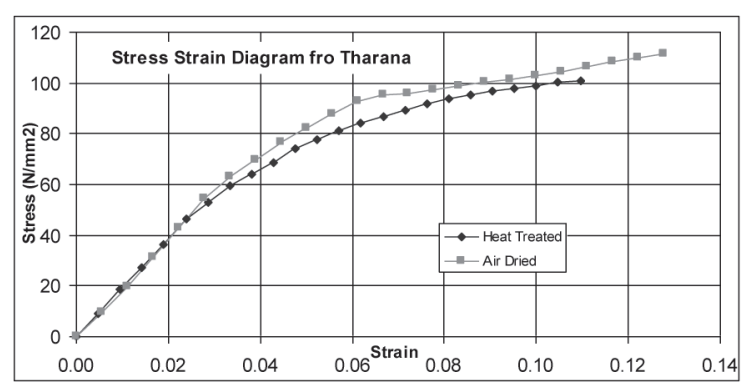

Figure 6 - Stress-Strain Diagram for Tharana

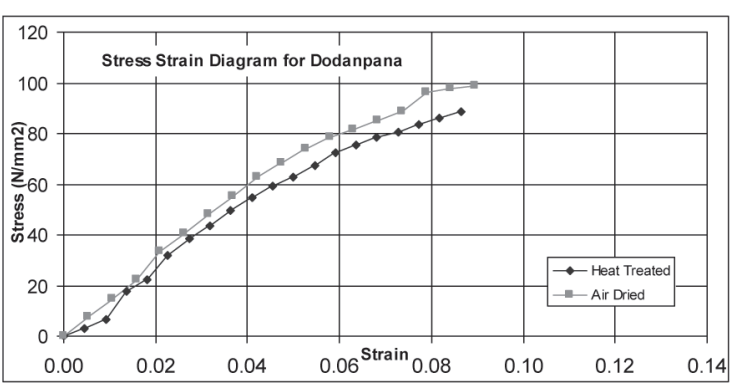

Figure 7 - Stress-Strain Diagram for Dodanpana

The survey revealed that villagers traditionally use tharana culms for construction of bissa and clay walls confirming that our ancestors had knowledge about its high tensile strength. The survey further revealed that Veval is used to produce baskets, furniture and decorations but not so much for structural purposes. This is consistent with the experimental findings of this study that Veval has the lowest tensile strength.

Also Table 1 clearly shows that the tensile strengths obtained for air dried specimens are higher than that obtained for heat treated specimens with respect to all the six varieties of woody plant materials.

Table 1 - Tensile strength of woody plant materials with respect to seasoning

\begin{tabular}{|c|c|c|c|c|}
\hline \multirow[t]{3}{*}{ Type } & \multicolumn{4}{|c|}{ Tensile strength $\left(\mathrm{N} / \mathrm{mm}^{2}\right)$} \\
\hline & \multirow{2}{*}{$\begin{array}{l}\text { Air } \\
\text { Dried } \\
(A D)\end{array}$} & \multirow{2}{*}{$\begin{array}{l}\text { Heat } \\
\text { Treated } \\
(\mathrm{HT})\end{array}$} & \multicolumn{2}{|c|}{ Variation } \\
\hline & & & $\begin{array}{l}\text { Abs. } \\
\text { from } \\
\text { AD }\end{array}$ & $\begin{array}{l}\% \text { of } \\
\mathrm{AD}\end{array}$ \\
\hline Veval & 17.7 & 14.9 & -2.8 & -15.8 \\
\hline Una & 24.1 & 16.1 & -8.0 & -33.2 \\
\hline Eraminiya & 88.7 & 87.9 & -0.8 & -0.9 \\
\hline Kooratiya & 102.3 & 71.9 & -30.4 & -29.7 \\
\hline Tharana & 111.5 & 101.1 & -10.4 & -9.3 \\
\hline Dodanpana & 98.9 & 88.5 & -10.4 & -10.5 \\
\hline
\end{tabular}

According to Table 1, Una records the highest decrease $(33.2 \%)$ in tensile strength due to heat treatment over air drying. The minimum variation $(0.9 \%)$ in tensile strength is recorded by Eraminiya. The ability of Eraminiya to withstand the heat treatment without a significant concomitant loss in tensile strength could be ascribed to it being formed with highly fibrous material. While the individual fibres of Eraminiya are strong they are densely and uniformly packed across the cross section. Veval is not formed with fibrous material and instead its core is formed with a weak material and only the outer portion is formed with a hard material. Tharana which recorded the 
highest tensile strength could withstand the effects of heat treatment with only a marginal loss in tensile strength (9.3\%).

\subsection{Elongation and Strain Characteristics of Woody plant Materials}

The tensile strength of woody plant material is a decisive factor in the choice of their use as an alternative material to mild steel reinforcement. Therefore, a good understanding about the stress/strain relationship of woody plant materials is of great importance. Figures 2 to 7 showing stress- strain diagrams for the six types of woody plant materials were useful in comparing characteristics among them. It is apparent from these figures, that the stressstrain curves for Eraminiya, Dodanpana, Tharana and Kooratiya have higher gradients indicating higher elastic moduli. In contrast, Una has a lower gradient and Veval has the lowest gradient in the respective stress-strain diagrams.

Table 2 - Strain at failure load of woody plant materials with respect to seasoning

\begin{tabular}{|c|c|c|c|c|}
\hline \multirow[t]{3}{*}{ Type } & \multicolumn{4}{|c|}{ Strain at failure load } \\
\hline & \multirow{2}{*}{$\begin{array}{l}\text { Air } \\
\text { dried } \\
\text { (AD) }\end{array}$} & \multirow{2}{*}{$\begin{array}{l}\text { Heat } \\
\text { Treated } \\
(\mathrm{HT})\end{array}$} & \multicolumn{2}{|c|}{ Variation } \\
\hline & & & $\begin{array}{l}\text { Abs. } \\
\text { from } \\
\text { AD }\end{array}$ & $\begin{array}{l}\% \text { of } \\
\mathrm{AD}\end{array}$ \\
\hline Veval & 0.14 & 0.10 & -0.04 & -28.6 \\
\hline Una & 0.03 & 0.04 & +0.01 & 33.3 \\
\hline Eraminiya & 0.07 & 0.12 & +0.05 & 71.4 \\
\hline Kooratiya & 0.08 & 0.10 & +0.02 & 25.0 \\
\hline Tharana & 0.13 & 0.11 & -0.02 & -15.4 \\
\hline Dodanpana & 0.09 & 0.09 & 0.00 & 0.0 \\
\hline
\end{tabular}

Table 2 shows the maximum strain a member could sustain before its failure, for both seasoning techniques for all six types of woody plant materials. According to Table 2, Una has the minimum strain for both seasoning techniques, while Veval recorded the maximum strain under air drying. The results reflect that the effect of the type of seasoning on the failure strains do not follow a particular pattern, but depends on the woody plant type. This indicates that heat treatment of Una, Eraminiya and Kooratiya increases ductility at failure. While Veval and Eraminiya have the maximum variation in strain, Dodanpana shows no variation in strain.

\subsection{Volumetric stability}

Volumetric stability which incorporates both cross sectional area stability and length stability is an important consideration when indigenous woody plant materials are used as reinforcing material embedded in mortar or concrete, because its bondage is susceptible to reduce with shrinking. The volume can change either due to reduction in the cross sectional area or the length, each situation having different impacts. When the cross sectional area of the wooden tendon shrinks, there could be separation from rigid surrounding material resulting in weak stress transfer. However, a decrease in length of an embedded reinforcement in a rigid body would create a pretension, which would be beneficial for the flexural capacity of the composite material. Hence, in a study that dwells on studying the impact of drying shrinkage on the tensile capacity of composite members in which the woody plant material is used to carry the tensile load, the behaviour of shrinkage in longitudinal and cross sectional directions have to be dealt with separately. Table 3 presents the percentage variations of cross sectional area and length due to drying shrinkage. It should be noted that these shrinkage values were obtained by further long term (one month) air drying of specimens previously seasoned using the two methods.

According to the test results, after heat treated seasoning, while Dodanpana recorded the lowest variation in cross sectional area, Tharana, Kooratiya and Una also showed relatively low variations. Veval and Eraminiya show very high variations in cross sectional area. It is

Table 3 - Percentage variations of cross sectional area and length due to shrinkage

\begin{tabular}{|c|c|c|c|c|c|c|c|c|c|c|}
\hline \multirow{3}{*}{$\begin{array}{l}\text { Woody } \\
\text { plant } \\
\text { material }\end{array}$} & \multicolumn{5}{|c|}{ Heat Treated } & \multicolumn{5}{|c|}{ Air Dried } \\
\hline & \multicolumn{4}{|c|}{ Cross sectional area } & \multirow[t]{2}{*}{ Length } & \multicolumn{4}{|c|}{ Cross sectional area } & \multirow[t]{2}{*}{ Length } \\
\hline & Left & Middle & Right & Avg & & Left & Middle & Right & Avg & \\
\hline Veval & 1.633 & 1.630 & 1.305 & 1.523 & 0.240 & 0.758 & 0.758 & 0.756 & 0.757 & 0.190 \\
\hline Una & 0.198 & 0.198 & 0.395 & 0.264 & 0.166 & 1.189 & 0.994 & 0.993 & 1.058 & 0.433 \\
\hline Eraminiya & 0.198 & 2.164 & 2.164 & 1.509 & 0.082 & 1.550 & 1.294 & 1.294 & 1.379 & 0.328 \\
\hline Kooratiya & 0.245 & 0.245 & 0.245 & 0.245 & 0.077 & 1.238 & 1.237 & -1.246 & 0.410 & 0.333 \\
\hline Tharana & 0.223 & 0.223 & 0.223 & 0.223 & 0.080 & 0.980 & 0.980 & 0.980 & 0.980 & 0.246 \\
\hline Dodanpana & 0.112 & 0.112 & 0.112 & 0.112 & 0.081 & 0.252 & 0.252 & 0.252 & 0.252 & 0.089 \\
\hline
\end{tabular}


noteworthy to state that for air drying seasoning, the pattern of results for variation in cross sectional area is somewhat similar to that under heat treatment. Eraminiya, showed the highest variation in cross sectional area under heat treatment and air drying.

While Veval recorded the highest length variation $(0.24 \%)$ under heat treated seasoning, Una displayed the highest length variation $(0.43 \%)$ under air drying category. According to Table 3, Una is poor in withstanding longitudinal shrinkage under both seasoning methods. Dodanpana showed its stability in resisting longitudinal shrinkage under both seasoning categories. Eraminiya and Kooratiya showed similar susceptibility to length variations.

\subsection{Advantages of Knots and Irregularities in Woody plant Materials}

In practice indigenous woody plant materials are used after removing the bark, without removing knots and other irregularities. It is logical to assume that bondage of woody plant material with the cement mortar would increase when the knots and irregularities are present. Therefore, in a real scenario when these materials are used as reinforcements with cement mortar, the bondage would be enhanced. The knots and irregularities in woody plant material could be considered analogous to ribs in steel reinforcement.

\section{Conclusion}

1.) At least four woody plant materials namely, Tharana (111.5 MPa), Kooratiya (102.3 MPa), Dodanpana (98.6 MPa) and Eraminiya (88.7 $\mathrm{MPa})$ show appreciable tensile strength that warrant their use as a composite material with cement mortar. Since these have tensile strength in the region of $35 \%-50 \%$ that of Mild Steel reinforcement $(250 \mathrm{MPa})$ they would have a potential use as reinforcement, at least in rural areas. However, Veval and Una exhibited inadequate tensile strength for practical applications as reinforcement.

2.) Appropriate adoption of the seasoning technique is a vital consideration when woody plant materials are used as a composite material, the main purposes of seasoning being either to increase the strength or to enhance the durability, or both. The research concluded that, though it consumes a substantial time, natural open air drying, as against the heat treatment, produces greater tensile strength. While Una and Kooratiya are highly susceptible to loose strength under heat treatment, Dodanpana and Tharana can successfully withstand heat treatment. Although air drying is a time taking process, for rural non commercial usage this seasoning technique can be recommended as a superior seasoning technique.

3.) As for strain at failure, three woody plant materials namely, Una, Eraminiya and Kooratiya, exhibited higher ductility under heat treatment. In contrast, the other three materials namely, Veval, Tharana and Dodanpana exhibited lower ductility for heat treatment. This shows that no clear correlation could be established between ductility and the seasoning techniques.

4.) Volume stability was evaluated in terms of both cross sectional area stability and length stability. While Dodanpana records the lowest variation in cross sectional area, Tharana, Kooratiya and Una also showed relatively high resistance to shrinkage. For both seasoning techniques, Eraminiya recorded the widest cross sectional area variation due to shrinkage. As for length variation which is a desirable property, Eraminiya, Kooratiya, Tharana and Dodanpana under both seasoning techniques showed similar results.

5.) Woody plant materials namely, Kooratiya Tharana and Dodanpana can be recommended as suitable materials to be used as reinforcement in cement mortar because of positive attributes such as; tensile strength, cross sectional area stability and length stability. These materials could also be used to substitute mild steel reinforcements in concrete members when relatively low flexural capacity is required. These materials could be easily obtained and seasoned in rural areas for limited applications as stated above.

\section{References}

1. Aziz, M. A., Paramasivam and Lee, S. L., "Prospects for Natural Fiber Reinforced Concretes in Construction", Volume 3, Number 2, 1981, pp 123132. 
2. Comino, E., Marengo, P., Rolli, V., "Root Reinforcement Effect of Different Grass Species: A Comparison Between Experimental and Models Results", Journal of Soil and Tillage Research, Vol. 110, 2010, pp. 60-68.

3. Defoirdt, N., Biswas, S., De Vriese Linde De, Ngoc Tran L., Acker, Van Acker, J, Ashan Q, Gorbatikh, L, Van Vuure A, Verpoest, I, "Assessment of the Tensile Properties of Coir, Bamboo and the Jute", Journal of Composites:, Part A 41, 2010, 588-595.

4. Ghavami, K., "Bamboo as Reinforcement in Structural Concrete Elements", Journal of Cement and Concrete Composites, 2, 2005, 637-649.

5. Ramasamy, H.S., Ahuja, B.M., Krishnamoorthy, S., "Behaviour of Concrete Reinforced with Jute, Coir and Bamboo Fibres", 'Journal of The International Journal of Cement Composites and Lightweight Concrete', 1983, Volume 5, Number 1.

6. "Fibre-Reinforced Cement and Concrete", Proceedings, RILEM Symposium, London Sept. 1975, The Construction Press, Hornby, 1975, pp. 459 . 